\title{
The Mean Evolution and Variability of the Asian Summer Monsoon: Comparison of ECMWF and NCEP/NCAR Reanalyses
}

\author{
H. Annamalai \\ J.M. Slingo \\ K.R. Sperber \\ K. Hodges
}

This paper was prepared for submittal to the

National Oceanic and Atmospheric Administration/ University of Miami/American Meteorological Society 23rd Climate Diagnostics and Prediction Workshop

Miami, FL

October 26-30, 1998

April 21, 1999

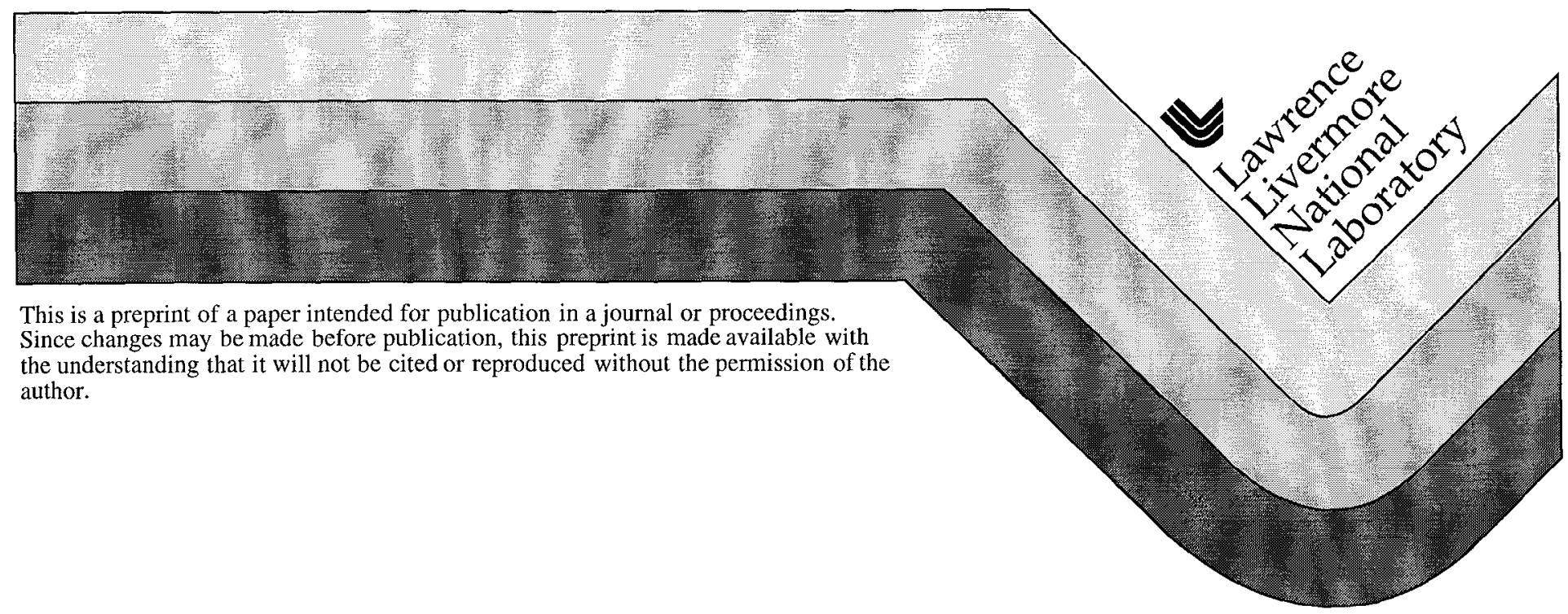




\section{DISCLAIMER}

This document was prepared as an account of work sponsored by an agency of the United States Government. Neither the United States Government nor the University of California nor any of their employees, makes any warranty, express or implied, or assumes any legal liability or responsibility for the accuracy, completeness, or usefulness of any information, apparatus, product, or process disclosed, or represents that its use would not infringe privately owned rights. Reference herein to any specific commercial product, process, or service by trade name, trademark, manufacturer, or otherwise, does not necessarily constitute or imply its endorsement, recommendation, or favoring by the United States Government or the University of California. The views and opinions of authors expressed herein do not necessarily state or reflect those of the United States Government or the University of California, and shall not be used for advertising or product endorsement purposes. 
The Mean Evolution and Variability of the Asian Summer Monsoon: Comparison of ECMWF and NCEP/NCAR Reanalyses

\author{
H. Annamalai ${ }^{1}$, J. M. Slingo ${ }^{1}$, K. R. Sperber ${ }^{2}$ and K. Hodges $^{3}$
}

${ }^{1}$ Centre for Global Atmospheric Modelling, Dept. of Meteorology, University of Reading, UK

${ }^{2}$ Program for Climate Model Diagnosis and Intercomparison, LLNL, Livermore, USA

${ }^{3}$ Environmental Systems Science Centre, Dept. of Geography, University of Reading, UK

The behaviour of the Asian Summer Monsoon is compared using the European Centre for Medium Range Weather Forecasts Reanalysis (ERA) and the National Centers for Environmental Prediction/National Center for Atmospheric Research (NCEP/NCAR) reanalysis (Kalnay et al. 1996). The goals of this paper are to identify common features between the reanalyses, to assess their robustness for model validation, and, especially, to use reanalyses to develop our understanding of the mean evolution of the Asian Summer Monsoon and the characteristics of its interannual and intraseasonal variability (Annamalai et al. 1999).

The June-September climatologies (1979-95) are evaluated in Figure 1. At $850 \mathrm{hPa}$ the Somali Jet is stronger and more zonal in NCEP/NC.AR (Figs. 1a-b), whereas in ERA it extends further north, the differences being about $5 \mathrm{~ms}^{-1}$ (not shown). At 200hPa, Figs. 1c-d, the equatorial easterlies are systematically stronger in NCEP/NCAR than in ERA. The differences in the seasonal mean winds are not small, and suggest that in data sparse regions the reanalyses may be influenced by the forecast models, particularly the physical parameterizations, since the tropical circulation is driven by diabatic heating primarily associated with latent heat release due to convection. Figs. 1ef show the rainfall climatologies based upon the 24-hour forecast. The higher horizontal resolution used in ERA is evident in the orographic nature of the precipitation distribution, particularly over the Indian subcontinent and S.E. Asia where ERA compares more favourably to the high resolution Legates and Willmott (1992) climatology (not shown). Compared to both Xie and Arkin (1996) and Legates and Willmott (1992) the NCEP/NCAR reanalysis has too little rainfall over the west Pacific and too much over China, whereas ERA underestimates the rainfall over peninsular India. The influence of the forecast precipitation distribution on the analysed winds has been investigated by comparing the difference in the analysed divergent circulations with those in the forecast precipitation. In the upper troposphere, the relationship is very strong suggesting that the difference in the analysed winds may be associated with the first guess provided by the forecast model. Thus, the biases in the forecast precipitation distribution in the NCEP/NCAR reanalysis (Figs. 1e), with the shift in the implied heating distribution from the west Pacific to S.E. Asia, may be partially responsible for the much stronger upper level easterlies over the Indian Ocean. Similarly, the westwards extension of the easterly jet over Africa in NCEP/NCAR may be associated with the greater rainfall amounts over the equatorial western Indian Ocean which reach to the Somali coast (Fig. 1e). This suggests that the upper level winds provided by the NCEP/ NCAR reanalysis may be less reliable than those given by ERA.

On interannual time scales differences between the reanalyses still exist which result in inconsistencies in the definition of weak and strong monsoon years based on the large scale wind shear based Dynamical Monsoon Index (DMI, Fig. 1g) and all-India Rainfall (AIR) anomalies (Fig. 1h). Whilst the reanalyses show better agreement for the DMI, the identification of weak/ strong monsoons in terms of regional precipitation anomalies is problematic, and must therefore still be based on observational data. In the $850 \mathrm{hPa}$ circulation two dominant modes of interannual variability have been identified which together explain nearly $50 \%$ of the variance. That there is no single mode which describes the interannual variability demonstrates why it is proving difficult to understand and predict monsoon behaviour; it is the interactions of these modes that gives rise to the monsoon circulation in a given year, and it is the subtle variations in the monsoon circulation 
that give rise to the regional precipitation anomalies.

The reanalyses show a common dominant mode of intraseasonal variability which describes the latitudinal displacement of the tropical convergence zone from its oceanic to continental regime and essentially captures the low frequency active/break cycles of the monsoon associated with northward propagating events. The consistency between the reanalyses means that this mode is robust and should be captured by GCMs. Similarly, the statistics on tropical cyclones and monsoon depressions are also in reasonable agreement and thus provide a baseline against which GCMs can be validated.

The relationship between interannual and intraseasonal variability has been investigated by considering the probability density functions (PDF's) of the principal components of the dominant modes of subseasonal variability. The PDF's for EI Niño and La Niña years indicate that El Niño predisposes the system to more break spells on intraseasonal time scales. See Sperber et al. (1999, this volume) for a more complete discussion of the relationship of intraseasonal and interannual variability during the Asian summer monsoon.

Acknowledgment. This work was performed under the auspices of the U.S. Department of Energy Environmental Sciences Division at the Lawrence Livermore National Laboratory under Contract W-7405-ENG-48.

Annamalai, H., J. M. Slingo, K. R. Sperber, and K. Hodges (1999) The mean evolution and variability of the Asian summer monsoon: comparison of ECMWF and NCEP/NCAR reanalyses. Mon. Wea. Rev. (in press)

Kalnay, E., M. Kanamitsu, R. Kistler, W. Collins, D. Deaven, L. Gandin, M. Iredell, S. Saha, G. White, J. Woollen, Y. Zhu, M. Chelliah, W. Ebisuzaki, W. Higgins, J. Janowiak, K.C. Mo, C. Ropelewski, J. Wang, A. Leetma, R. Reynolds, R. Jenne and D. Joseph, 1996: The NCEP/ NCAR 40-year reanalysis project. Bull. Amer. Met. Soc., 77, 437-471.

Legates, D. R and C. J. Willmoll, 1990: Mean, seasonal and spatial variability in gauge corrected global precipitation. Int. J. Climatol., 10, 111-127.

Sperber, K. R., J. M. Slingo, and H. Annamalai (1999) The relationship between intraseasonal and interannual variability during the Asian summer monsoon. (this volume)

Xie, P and P. Arkin, 1996: Analyses of global monthly precipitation using gauge observations, satellite estimates and numerical model predictions. J. Climate, 9, 840-858. 

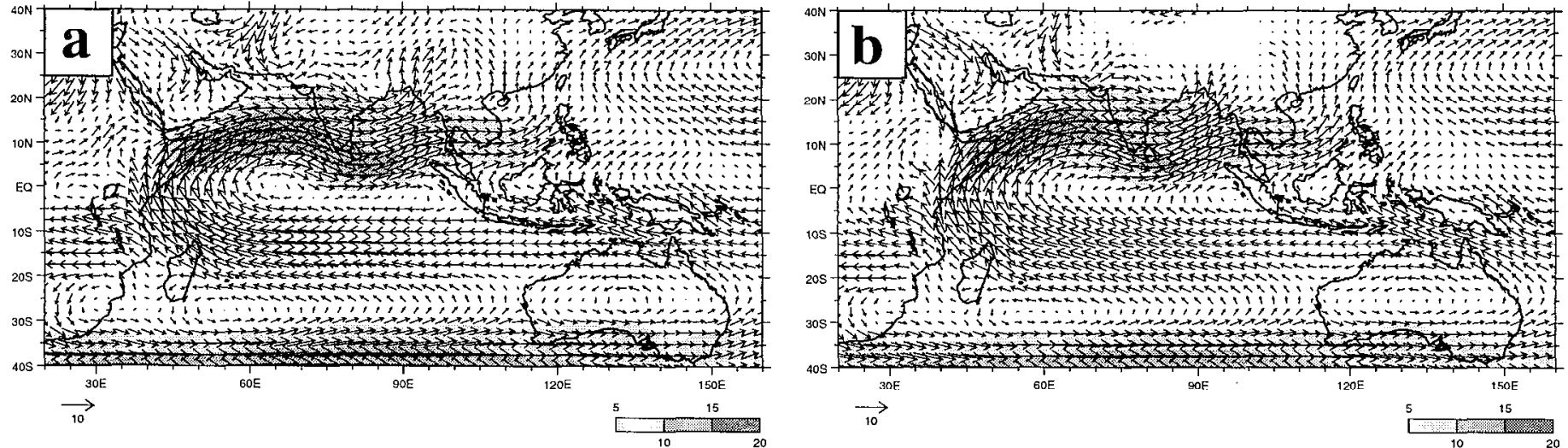

NCEP

\section{$200 \mathrm{hPa}$}
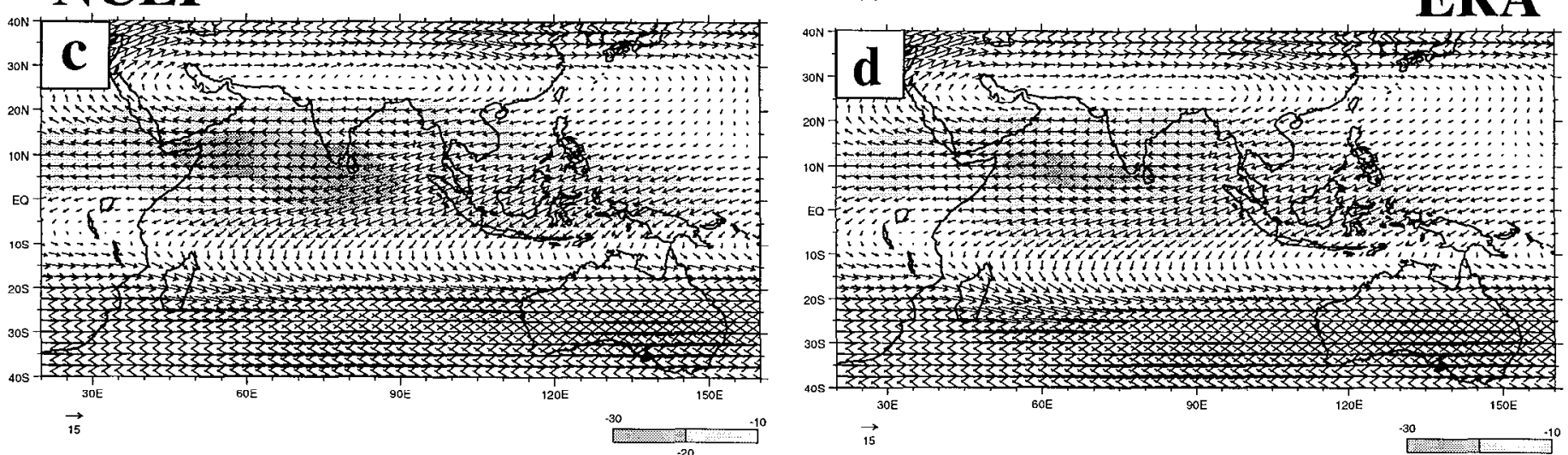

NCEP

\section{Precipitation}

ERA
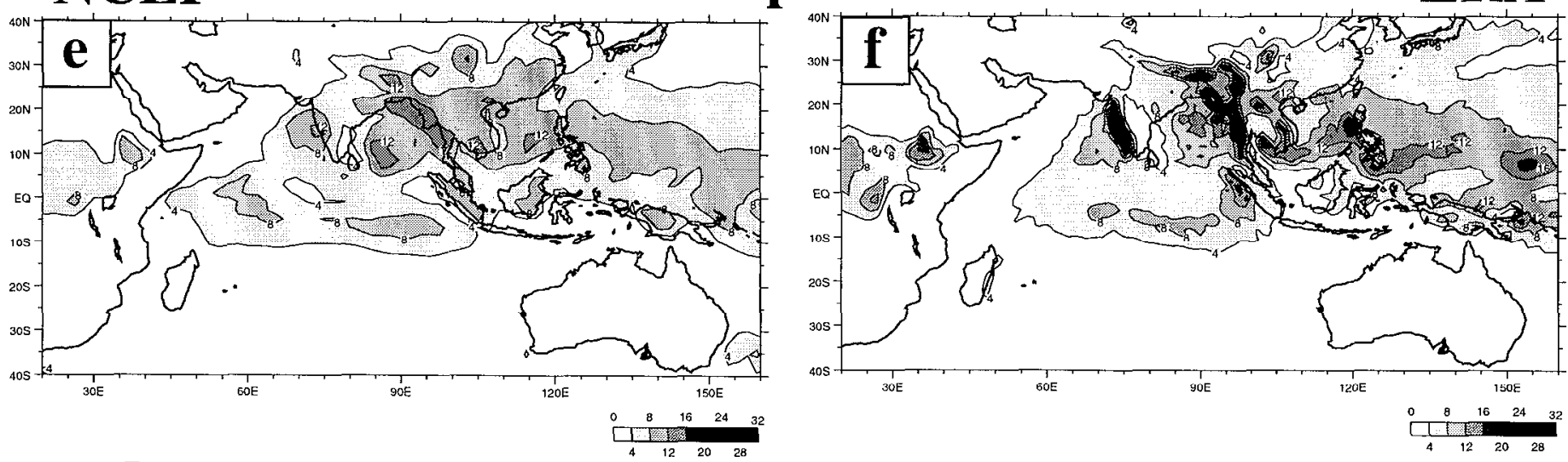

DMI

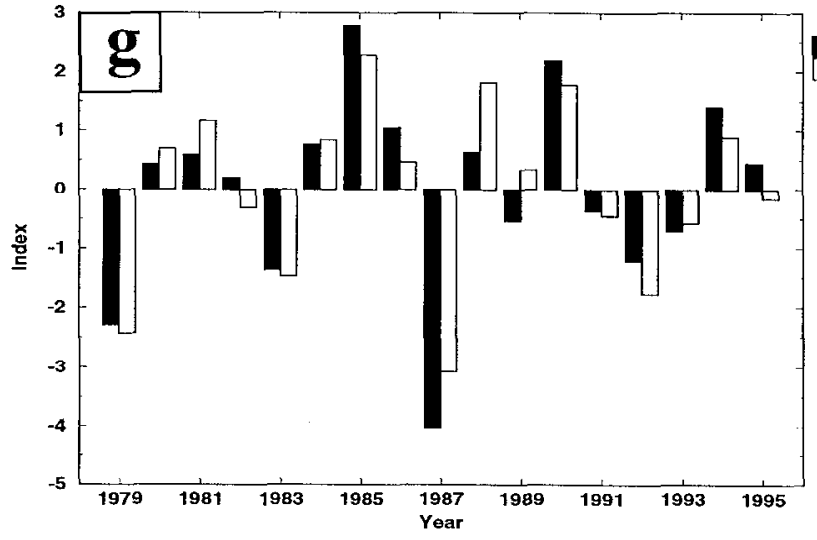

AIR

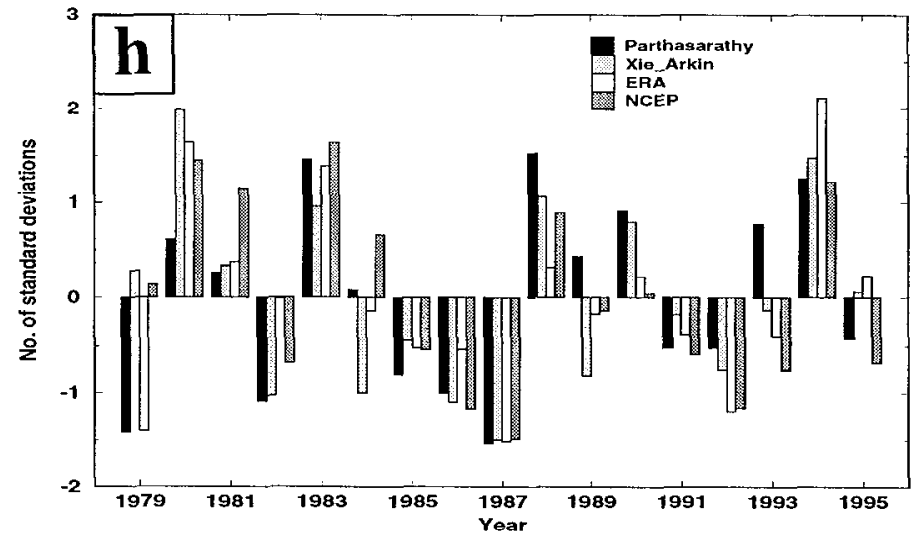

